\title{
Marketing de Relacionamento: um estudo em pousadas de Marechal Floriano - ES
}

\section{Relationship Marketing: a study in inns of Marechal Floriano - ES}

\section{Marketing de Relación: um estudio em albergues de Marechal Floriano - ES}

Anciéle Busato Krohling ${ }^{1}$

Anderson Soncini Pelissari ${ }^{2}$

\section{RESUMO}

O setor de turismo teve um grande crescimento nas últimas décadas, evidenciado pelo aumento na participação relativa no setor de serviços. Os setores de turismo e serviços tornaram-se mais competitivos, e diante deste cenário, um elemento que pode ser visto como estratégico para a fidelização de clientes é o marketing de relacionamento, que busca implantar ações no sentido de personalizar as relações com os clientes. Neste trabalho são identificadas e descritas as ações de marketing de relacionamento, que as pousadas estão utilizando junto a seus clientes, objetivando colaborar com os donos das pousadas verificando se as ações empreendidas por eles são suficientes e formas de melhoramento das ações levando ao crescimento da atividade turística. O universo da presente pesquisa é formado pelas pousadas do município de Marechal Floriano, cujos sujeitos da pesquisa foram seus dirigentes. Para obtenção de dados, optou-se pela amostra não-probabilística intencional, constituída de 03 pousadas e sendo entrevistados os dirigentes, obtendo informações acerca das ações de marketing de relacionamento empreendidas. A pesquisa revelou que as principais ações de marketing de relacionamento são: o atendimento cordial; contato com os clientes por telefone para comunicar eventos; adoção de banco de dados e estabelecimento de parcerias com empresas vizinhas.

Palavras-chave: Turismo. Pousadas. Serviços. Marketing de relacionamento. Marechal Floriano.

\section{ABSTRACT}

The tourism sector has greatly increased in recent decades, as evidenced by the increase in the relative share in the service sector. The tourism and service sectors have become more competitive, and before this scenario, an element that can be seen as strategic for customer

\footnotetext{
${ }^{1}$ Graduada em Administração pela Universidade Federal do Espírito Santo (UFES). Brasil. ancielebusato@gmail.com

${ }^{2}$ Doutor em Engenharia da Produção. Professor do Programa de Mestrado em Administração da Universidade Federal do Espírito Santo (PPGADM - UFES). Brasil. asoncinipelissari@gmail.com
} 
loyalty is relationship marketing, which seeks to implement actions to personalize relationships with customers. In this work are identified and described the actions of relationship marketing, that guesthouses are using with customers, aiming to cooperate with the owners of the inns checking whether the actions taken are sufficient for them and ways of improving actions leading to growth of activity tourist. The universe of this research is formed by the lodgings of the municipality of Marechal Floriano, whose subjects were their leaders. To obtain data, we opted for intentional non-probabilistic sample, consisting of 03 lodges and being interviewed leaders, getting information about the actions of relationship marketing undertaken. The survey revealed that the main actions of relationship marketing are: the warm; touch with customers by telephone to report events; adoption database and partnerships with neighboring businesses.

Keywords: Tourism. Inns. Services. Relationship Marketing. Marechal Floriano.

\section{RESUMEN}

El sector del turismo ha aumentado considerablemente en las últimas décadas, como lo demuestra el aumento de la participación relativa en el sector de servicios. Los sectores del turismo y de servicios se han vuelto más competitivo, y ante este escenario, un elemento que puede ser visto como estratégico para la lealtad del cliente es el marketing relacional, que busca implementar acciones de personalizar las relaciones con los clientes. En este trabajo se identifican y describen las acciones de marketing relacional, casas de huéspedes que se utilizan con los clientes, con el objetivo de cooperar con los dueños de las posadas comprobar si las medidas adoptadas son suficientes para ellos y las formas de mejorar las acciones que conducen a un crecimiento de la actividad turístico. El universo de esta investigación está formado por los alojamientos del municipio de Marechal Floriano, cuyos temas eran sus líderes. Para obtener los datos, se optó por no probabilística intencional de la muestra, que consta de 03 casas de campo y se entrevistó a líderes, obtener información sobre las acciones de marketing relacional emprendidas. La encuesta reveló que las principales acciones de marketing relacional son: la tibia; contacto con los clientes por teléfono para informar de los acontecimientos, la adopción y la base de datos de asociaciones con las empresas vecinas.

Palabras clave: El turismo. Albergues. Servicios. Marketing de Relación. Marechal Floriano.

\section{INTRODUÇÃO}

No mundo globalizado e em constante mudança, onde a internet traz a facilidade de comprar ou de se comunicar sem precisar sair de casa, os clientes estão cada vez mais exigentes buscando produtos de maior qualidade e serviços que satisfaçam suas expectativas (SALIBY, 1997). Diante deste cenário, e com a crescente competitividade nos setores de Turismo e de 
Serviços, um elemento que pode ser visto como estratégico para a fidelização de clientes é o Marketing de Relacionamento, que busca implantar ações no sentido de personalizar as relações com o cliente e tratá-lo como único (SILVA, 2008). É importante perceber, que o Marketing de Relacionamento sugere a manutenção de relacionamentos entre organizações, entre organizações e membros de canais de distribuição e entre organizações e clientes individuais (ROCHA; LUCE, 2006). No entanto, é sobre o relacionamento com os clientes finais que este trabalho está estruturado.

O tema abordado neste estudo se mostra relevante, pois o turismo é uma das atividades econômicas que mais crescem mundialmente e as pousadas mostram-se como de vital importância para o desenvolvimento da atividade turística local, uma vez que, atraem novos visitantes e expõe produtos locais, além de gerar emprego e renda para a comunidade (LACERDA, 2008). A escolha deste tipo de hospedagem para a realização do estudo se justifica, uma vez que este despontou no mercado como uma alternativa de hospedagem acessível e agradável, e que atende às necessidades dos hóspedes. No entanto, há pouco referencial teórico sobre este assunto (LACERDA, 2008). Outro fator determinante para a escolha das pousadas como objeto de estudo, é a forma como as relações entre empresa e clientes são desenvolvidas. Nas pousadas, os hóspedes buscam momentos de lazer e descanso dentro da própria pousada, por isso o atendimento faz toda a diferença, além disso, o relacionamento entre empresa e clientes se dá de uma forma mais próxima e intensa.

É neste contexto que esse trabalho se justifica, pela importância de conhecer quais estratégias de Marketing de Relacionamento as pousadas de Marechal Floriano estão adotando, e quais ainda poderiam ser adotadas como forma de melhorar o relacionamento turístico no município. Os resultados obtidos nesse estudo podem interessar aos donos das pousadas, como forma de avaliar se as ações de Marketing de Relacionamento empreendidas por eles são suficientes, bem como podem ser definidas sugestões de melhoramento das ações. Para a comunidade acadêmica, esta pesquisa torna-se relevante devido ao objeto de estudo ter sido ainda pouco explorado. Diante da situação apresentada, chegou-se ao seguinte problema de pesquisa: Quais estratégias de Marketing de Relacionamento as pousadas de Marechal Floriano estão desenvolvendo junto a seus clientes? Assim, o objetivo geral deste trabalho é 
identificar e descrever quais estratégias de Marketing de Relacionamento as pousadas de Marechal Floriano/ES estão desenvolvendo junto a seus clientes.

O município de Marechal Floriano localiza-se na região serrana do Espírito Santo, distante 47 km da capital Vitória, e integra as montanhas capixabas juntamente com os municípios de Afonso Cláudio, Brejetuba, Castelo, Conceição do Castelo, Domingos Martins, Laranja da Terra, Vargem Alta e Venda Nova do Imigrante. A região possui algumas paisagens ainda pouco conhecidas pelos turistas, caracteriza-se por topografia montanhosa, riqueza de recursos hídricos e ótimos lugares para caminhada e contato com a Mata Atlântica. A região tem se fortalecido e oferece diversas possibilidades de lazer e de desenvolvimento do setor turístico (SEDETUR, 2006).

A seguir, é apresentada a revisão da literatura sobre turismo nas montanhas capixabas e marketing de relacionamento. Posteriormente, são descritos os aspectos metodológicos da investigação utilizados, apresentando o universo e a amostra, a caracterização das pousadas, a coleta de dados e o tratamento dos dados. Em seguida, apresenta-se a análise e discussão dos dados levantados a partir do estudo de caso realizado. Por fim, têm-se as considerações finais e as sugestões para trabalhos futuros.

\section{Fundamentação Teórica}

\subsection{Turismo nas montanhas capixabas}

O relevo montanhoso e a influência de culturas europeias, principalmente alemã e italiana, fazem com que a região serrana se apresente como atrativo para os turistas que apreciam o clima frio e a culinária regional. Ao considerarmos esses elementos como parte do pacote turístico, conclui-se que a preservação dos mesmos, depende da manutenção dos costumes e tradições dos imigrantes e da preservação dos recursos naturais (SEDETUR, 2006). As montanhas capixabas têm recebido maior número de turistas durante o inverno, devido ao clima frio típico da região, que atrai muitos visitantes. O fluxo turístico da região é predominantemente capixaba, sendo de $75 \%$ dos visitantes. Observa-se ainda, um fluxo significante de turistas de Minas Gerais e Rio de Janeiro, com 9\% e 5\% respectivamente (SEDETUR, 2006). 
De acordo com pesquisa realizada pela Futura em 2011, com moradores da Grande Vitória, e que visitaram as montanhas capixabas no inverno do mesmo ano, a avaliação do pacote turístico foi positiva. Foram realizadas entrevistas com 305 pessoas sendo que a avaliação de ótimo ou bom, para a infra-estrutura hoteleira, obteve $64,6 \%$, restaurantes $64,9 \%$, opções de lazer $58 \%$ e atendimento ao turista $63,3 \%$, que avaliaram positivamente.

Nos municípios de Marechal Floriano, Domingos Martins e Venda Nova do Imigrante, que fazem parte da região das montanhas capixabas, na alta temporada de 2006, destacavam-se como principais meios de hospedagem: a acomodação em casa de parentes, correspondendo a $50 \%$ dos turistas que visitavam a região, e $23 \%$ faziam uso de pousadas, hotéis e apart-hoteis (SEDETUR, 2006).

Como já observado, para a realização de qualquer atividade turística, é preciso ter um amplo complexo de serviços que tornem o turismo possível devido à utilização dos recursos locais e naturais. Necessita-se de infra-estrutura envolvendo saneamento básico, transportes eficientes, educação e saúde, e claro, restaurantes, hotéis e pousadas (GOUVÊA; YAMAUCHI, 1999; GOUVÊA; NIÑO, 2006; BARRETO, 2003). Diante deste cenário, surge a necessidade de conhecimento e maior entendimento do marketing de relacionamento.

\subsection{Marketing de relacionamento}

Em uma época de informação, torna-se cada vez mais difícil fabricar uma imagem. A distância entre percepção e realidade está diminuindo e os consumidores passaram a ter tantas opções que se tornam cada vez mais instáveis (MCKENNA, 1997). Com o aumento da globalização e consequente aumento da competitividade, sobreviver em ambientes tão instáveis fica cada vez mais difícil (MELLO; VIEIRA, 2008). De acordo com McKenna (1997), nesses ambientes é preciso construir bases sólidas, por isso as empresas precisam construir relações com fornecedores, clientes e outras pessoas importantes do mercado. Ainda segundo o autor, estas relações são mais importantes que preços baixos, promoções e tecnologias avançadas, e nesse tipo de relação, o ciclo de feedback é essencial, pois clientes e outras pessoas podem influenciar, na melhoria dos produtos e serviços através da participação nessas relações. 
O marketing tradicional sempre se concentrou em atrair novos clientes não se importando em cultivar os já existentes. Hoje, embora as empresas continuem se preocupando em buscar clientes, a ênfase deslocou-se para o marketing de relacionamento, que busca criar, manter e aprimorar relacionamentos duradouros com clientes e outros interessados (KOTLER; ARMSTRONG, 2003). Gordon (1998, pág. 31) define o marketing de relacionamento como sendo "o processo continuo de identificação e criação de novos valores com clientes individuais e o compartilhamento de seus benefícios durante uma vida toda de parcerias". Para Mello e Vieira (2008, pág. 4) "relacionamento é um termo que sugere, de um modo geral, confiança e interação entre dois ou mais indivíduos”. O marketing de relacionamento surgiu para consolidar o relacionamento entre empresas e clientes, possibilitando o aumento do lucro e o tempo de duração de um cliente dentro de uma empresa (OLBRZYMEK; OLBRZYMEK; BRETZKE, 2005). Vários autores têm enriquecido o conceito de marketing de relacionamento, porém todos os conceitos têm em comum a busca pelo atendimento cada vez melhor das necessidades dos clientes, buscando um relacionamento duradouro de longo prazo que conduza a fidelização dos clientes e lucro para a empresa (NEGRETTO, 2007).

\subsubsection{Marketing de relacionamento focado no cliente}

Em um mercado competitivo, onde os clientes são o foco estratégico de muitas empresas, o marketing de relacionamento torna-se uma ferramenta importante para a sobrevivência e para o sucesso das organizações, com o principal objetivo de criar relacionamentos duradouros com seus clientes (GILBERTI; JEUNON; ANDRADE, 2007). Indiscutivelmente, os clientes são a peça-chave de qualquer negócio e as empresas estão sempre buscando atrair novos clientes, no entanto, o que muitas não percebem, é que a forma usada para atrair, é muitas vezes mais importante do que o número de clientes que se atrai (MCKENNA, 1997). Segundo estudos realizados, o custo para atrair um novo cliente pode ser cinco vezes maior que o custo para manter um cliente satisfeito (TONI; SCHULER, 2004; PEPPERS; ROGERS, 1994; BARNES, 2002).

Conservar clientes existentes pode representar lucro em situações em que é difícil conquistar novos clientes lucrativos, para substituir os clientes que partiram (GRÖNROOS, 2003). Os clientes-chave, além de representar um maior faturamento, podem ajudar de outras formas como, por exemplo, podem oferecer um feedback valioso, ajudando a empresa a desenvolver 
novas formas de aprimorar seu produto ou serviço (MCKENNA, 1997). Um dos principais sinais de declínio de um relacionamento é a ausência de reclamações por parte do cliente. Ninguém estará satisfeito durante um longo período, o cliente ou não está sendo sincero, ou não está sendo contatado. A ausência de sinceridade reflete o declínio da confiança e consequente deterioração do relacionamento (LEVITT, 1990).

Bowersox, Cooper e Closs (2006) definem quatro passos para implementação do Marketing de Relacionamento com clientes. São eles: Identificar os clientes; diferenciar os clientes; real interação, personalização do comportamento da companhia.

Identificar os Clientes Individuais - Quando a gestão de relacionamento é bem implantada, a empresa deve focalizar tanto a gestão com os clientes, quanto a gestão dos seus produtos, ao mesmo tempo, é preciso perceber que uma estratégia de relacionamento não é eficaz em todas as situações (KOTLER; KELLER, 2006). Embora possa parecer simples, muitas empresas pensam em grupos de clientes ao invés de pensar no cliente individual. Considerar o cliente como único é importante por que cada um pode apresentar uma necessidade diferente dos outros (BOWERSOX; COOPER; CLOSS, 2006). É preciso analisar quais segmentos responderão produtivamente ao marketing de relacionamento (KOTLER; KELLER, 2006).

Diferenciar os Clientes - Comerciantes bem sucedidos centralizam seus esforços em clientes que proporcionam maior retorno financeiro (BOWERSOX; COOPER; CLOSS, 2006). Firmino (2007) destaca que existem clientes mais lucrativos que outros, e que é importante identificar quais são esses mais lucrativos. Providenciar serviços com mesmo nível de qualidade para todos os clientes, não é vantagem do ponto de vista econômico, pois cada cliente pode ter um valor diferente para a empresa (BOWERSOX; COOPER; CLOSS, 2006). De acordo com Peppers e Rogers (1994), clientes que custam mais em tempo e esforços do que geram em termos de lucro para a empresa, podem ter um valor negativo. Portanto, para trabalhar com o marketing de relacionamento, é preciso localizar os usuários mais frequentes, de maior valor, ao invés de toda uma categoria. Esses clientes são responsáveis por um maior volume de compra e são mais propensos a fidelização.

Real Interação com os Clientes - Tem por objetivo melhorar a eficiência e a eficácia de custos. Trata de propor mecanismos de integração que gerem satisfação e lealdade dos 
clientes. A maioria das empresas utiliza a tecnologia para promover um melhor relacionamento com os clientes, tais como Database Marketing e o CRM - Gerenciamento de Relacionamento com o Cliente. Hoje, cada vez mais, as empresas buscam desenvolver programas de fidelidade para atrair e reter clientes. Uma empresa pode oferecer benefícios financeiros, ou econômicos, construindo valor e satisfação por meio de cartões de fidelidade e programa de pontos. Outra abordagem é acrescentar aos benefícios financeiros, o benefício social, dessa forma, a empresa aumenta seus vínculos com o cliente procurando saber das suas necessidades e desejos para personalizar seus produtos e serviços (KOTLER; ARMSTRONG, 2003).

Personalização do Comportamento da Companhia - As empresas devem adaptar alguns de seus comportamentos com base nas exigências do consumidor, isso pode significar personalizar um produto ou mudar um serviço.

O marketing de relacionamento como estratégia empresarial, traz algumas vantagens para os clientes: Recebem soluções específicas para seus desejos e necessidades; Reduz os riscos da compra e facilita no processo de decisão; Quando a compra possui riscos maiores, é importante conhecer o fornecedor; Oferece certo status social pelo fato de o cliente ser reconhecido, atendido de acordo com suas necessidades e recompensado por sua fidelidade (RIBEIRO; FLEURY, 2006).

\subsubsection{Estratégia de relacionamento}

Em seus estudos, Grönroos (2003) apresenta os três elementos táticos de uma estratégia de relacionamento:

- Buscar contato direto com os clientes e outros parceiros - O marketing de relacionamento sugere confiança e interação entre empresa e clientes (MELLO; VIEIRA, 2008), portanto as empresas devem tratar de conhecer muito bem seus clientes, além de dar prioridade ao contato face a face e fazer uso das tecnologias para chegar o mais próximo possível do cliente (GRÖNROOS, 2003).

- Montar um banco de dados com as informações necessárias sobre os clientes e outros - O banco de dados é capaz de formar um vínculo entre os clientes e a empresa. Esse vínculo sustenta o pós-marketing de duas maneiras: reconhecimento e relevância (VAVRA, 
1993). O reconhecimento significa conhecer verdadeiramente o valor de um cliente, percebendo sua existência e reconhecendo suas necessidades e desejos específicos. $\mathrm{O}$ reconhecimento fica evidente quando a opinião de um cliente é requisitada com frequiência e quando ele é convidado a fazer parte do processo de produção por exemplo. Já a relevância, será resultado do reconhecimento. À medida que os produtos ou serviços atendem às necessidades específicas de um cliente, ele sentirá o interesse da empresa por ele (VAVRA, 1993). Por isso, segundo Negretto (2007), um banco de dados deve ser sempre atualizado para atender às necessidades dos clientes e para a empresa ser capaz de surpreendê-lo e criar necessidades antes que os consumidores se deem conta delas.

- Se o banco de dados não existir, o relacionamento acontecerá de maneira parcial (GRÖNROOS, 2003). O banco de dados de clientes ajuda a implementar o pós-marketing e contribui para a criação de relacionamentos duradouros, visto que, a empresa poderá identificar seus clientes mais importantes e apresentar a eles a oferta ou serviço adequado em tempo correto. Da mesma forma, o desenvolvimento de novos produtos é facilitado ao se reconhecer quais clientes tem comprado, como o produto satisfaz o consumidor e se existiria a possibilidade de melhorar o desempenho do produto (VAVRA, 1993).

- Desenvolver um sistema de serviços que seja orientado para o cliente - Os processos de geração de valor da empresa devem ser voltados para os interesses dos clientes, ou seja, para satisfazer as necessidades do consumidor, produzindo e entregando uma oferta total de serviços.

- Grönroos (2003) ainda menciona os três requisitos estratégicos de uma estratégia de relacionamento. São eles:

- Redefinir o negócio como negócio de serviços - Competir com o produto central, na maioria dos casos não é suficiente, o que conta é competir com um pacote total, que inclui os produtos e os serviços necessários para a produção e entrega dos produtos. Dessa forma, ser competitivo também em serviços pode representar a chave para o sucesso.

- Adotar uma perspectiva gerencial de processos e não uma perspectiva funcional - Uma empresa que deseja ir mais longe e produzir valor total máximo, em uma tentativa de 
relacionamento duradouro com o cliente, deve adotar um gerenciamento de processos para todas as atividades da empresa. Dessa forma, o fluxo de trabalho é organizado e gerenciado como processos de criação de valor, que fortalece o desenvolvimento de relacionamentos.

- Estabelecer uma rede de parcerias para cuidar de todo o processo de serviços - No lugar de uma competição predatória, muitas empresas estão percebendo que devem colaborar para competir (TONI; SCHULER, 2004). Uma empresa não pode oferecer por si só, todos os serviços necessários aos clientes e torna-se muito caro adquirir todo o conhecimento e os recursos necessários para que elas produzam elementos requeridos na oferta (GRÖNROOS, 2003). Por isso, é mais vantajoso criar parcerias para dividir os custos de capital.

- Com relação ao desenvolvimento de parcerias, McKenna (1997), defende que é importante para as empresas de setores em rápida transformação, criarem relações estratégicas por diversos motivos:

- Para sobreviver no mercado atual, as empresas precisam dispor de diversas fontes de tecnologias, e nenhuma empresa pode desenvolver sozinha todas as soluções e tecnologias necessárias.

- O desenvolvimento de novas tecnologias, é um processo muito caro, é mais vantajoso para as empresas partilharem esses custos.

- A competição mundial faz com que empresas busquem mercados internacionais, por isso, muitas delas fazem alianças com empresas estrangeiras para ter acesso rápido a mercados e expandi-los, além de dividir os custos de capital.

- Para competir as empresas precisam dispor de conhecimentos administrativos, capacidade de distribuição e capital. As relações estratégicas podem proporcionar isso.

- Os benefícios trazidos para as empresas, com relação à adoção do marketing de relacionamento, no que diz respeito ao relacionamento com os clientes, são: a obtenção da satisfação, da confiança, do comprometimento e consequente fidelização dos clientes, além da propaganda boca a boca que os clientes satisfeitos promovem (MOTA; 
FREITAS, 2008). No próximo tópico discutir-se-á os elementos que de acordo com Kotler e Armstrong (2003), são a chave para a construção de relacionamentos duradouros.

\subsubsection{Valor e satisfação}

De acordo com Kotler e Armstrong (2003), a chave para a construção de relacionamentos duradouros, é a criação de valor e satisfação superior para os clientes, ainda segundo os autores, clientes satisfeitos têm mais probabilidade de se tornarem clientes fiéis.

\subsubsection{Valor para o cliente}

As organizações que adotaram o marketing de relacionamento puderam perceber que, por ser difícil entregar algo que o cliente valorize e que seja diferente da concorrência, a solução para competir em mercados turbulentos está em conhecer o cliente e ofertar valor superior (RIBEIRO; FLEURY, 2006). Um valor de mercado é o potencial que um produto tem de satisfazer os desejos e as necessidades dos clientes. O contexto ou a situação do cliente na hora da compra pode conferir maior ou menor valor ao produto ou serviço (GOUVEA; BIAZZI, 2007).

Um pacote de valor é a combinação de elementos tangíveis e intangíveis que os clientes avaliam ao decidir qual produto ou serviço deve ser adquirido. Quando uma empresa cria um pacote de valor que vai além das expectativas comuns, ela tem a capacidade de encantar o cliente (NICKELS; WOOD, 1999). Se o valor percebido pelo cliente de determinada marca atingir ou exceder suas expectativas, este cliente estará disposto a recompra, desde que possua recursos para tanto. Podemos dizer, portanto, que este cliente provavelmente será fiel à marca na hora da compra (GOUVEA; BIAZZI, 2007).

De fato, os clientes escolhem a oferta de marketing que lhe entregará maior valor e na hora da compra ele observa elementos como confiabilidade, durabilidade, prazo de entrega, e também fica atento aos custos totais atribuídos a compra, que incluem custos monetários e custos esperados de tempo, de energia e psicológico, (KOTLER; ARMSTRONG, 2003). É claro que não se deve considerar toda compra como totalmente racional. Os compradores possuem limitações que, em alguns casos, o benefício pessoal torna-se maior que o benefício da empresa (KOTLER; ARMSTRONG, 2003). 
No marketing de relacionamento, a compra não é o final do processo (LEVITT, 1990), os vendedores devidamente orientados para entregar valor ao cliente, continuam trabalhando em um relacionamento para garantir que o cliente se sinta satisfeito e propenso a realizar novas compras). Isso se torna fator fundamental na escolha do vendedor numa próxima vez (LEVITT, 1990). Espera-se que um cliente apresente reações de lealdade a uma empresa, na medida em que a empresa entregue mais valor a ele. Levando-se em conta que valor é uma meta superior e a lealdade um comportamento eventual, verifica-se que o nível de valor entregue, determina as ações do consumidor em relação à empresa (BREI; ROSSI, 2005). As empresas vendedoras devem primeiramente avaliar o valor total entregue ao cliente por suas ofertas e pelas ofertas do concorrente, para só então determinar um termo de comparação (KOTLER; ARMSTRONG, 2003).

\subsubsection{Satisfação do cliente}

De acordo com Gilberti, Jeunon e Andrade (2007), a chave para o relacionamento com os clientes, é o longo prazo, e o sucesso desse processo pode ser acompanhado pelos índices de satisfação e recompra. Para Vavra (1993), é somente por meio da satisfação dos consumidores que as estratégias de marketing de relacionamento terão sucesso.

Os consumidores criam expectativas sobre o valor dos produtos e serviços e tomam suas decisões de compra, baseado nessas expectativas. Por tanto, a satisfação do consumidor depende do desempenho real da oferta quando comparada com a expectativa do consumidor (KOTLER; ARMSTRONG, 2003). Podem existir clientes insatisfeitos, indiferentes ou satisfeitos. O consumidor estará insatisfeito quando o desempenho do produto ou serviço é aquém da expectativa de consumo existente, nesses casos o cliente pode fazer "propaganda" negativa do produto e em uma próxima oportunidade procurará a oferta de um concorrente. $\mathrm{O}$ consumidor estará indiferente quando o desempenho do produto ou serviço, apenas supre a expectativa existente, nesse caso o cliente não propaga negativamente o produto, mas ainda não cria um vínculo mais forte com a empresa. Porém, quando o produto ou serviço vai além das expectativas do consumidor, o cliente se sentirá satisfeito, propagando positivamente o produto e estabelecendo um vínculo mais forte com a empresa (OLBRZYMEK; OLBRZYMEK; BRETZKE, 2005). 
Para criar suas expectativas, os clientes baseiam-se em experiências anteriores, na opinião de amigos e pessoas próximas e nas promessas que o vendedor faz para tentar convencer o cliente. Se as empresas determinarem um nível muito baixo de expectativa, poderá satisfazer àqueles clientes que comprarem, mas atrairá um número muito pequeno de interessados na compra. Ao contrário, se as empresas determinarem um nível muito alto de expectativa e não conseguir entregar todo o valor proposto, o cliente ficará desapontado e insatisfeito (KOTLER; ARMSTRONG, 2003). O importante é possibilitar a satisfação do cliente pela personalização do atendimento, dos produtos, dos serviços, ou de seu conjunto. A estratégia deve focar em uma relação de interatividade e aprendizado contínuo, gerando valor e satisfação para um relacionamento duradouro e produtivo. Os clientes satisfeitos podem produzir muitos benefícios para a empresa, eles são menos sensíveis ao preço, falam bem da empresa e dos produtos para outras pessoas, e permanecem fiéis por um maior espaço de tempo (KOTLER; ARMSTRONG, 2003).

É importante lembrar que, o propósito do marketing é entregar valor para o cliente, mas com lucratividade para a empresa. Isso exige um determinado equilíbrio: a empresa deve levar valor superior e satisfação para os clientes, mas sem abandonar a lucratividade (KOTLER; ARMSTRONG, 2003). Portanto, a satisfação do cliente é um importante componente de sua fidelidade. Qualquer empresa pode perceber que é difícil conquistar a fidelidade do cliente sem antes entregar altos níveis de satisfação para ele (KOTLER; ARMSTRONG, 2003).

\section{Aspectos Metodológicos da Investigação}

A presente pesquisa, apresenta num primeiro momento, uma abordagem de natureza qualitativa. Essa abordagem pode descrever a complexidade de determinado problema, analisar a interação de variáveis, classificar processos dinâmicos e pode possibilitar um aprofundamento no entendimento do comportamento de indivíduos (RICHARDSON, 1989). $\mathrm{Na}$ pesquisa qualitativa os dados não estão sujeitos a análises de quantificação ou quantitativas (MCDANIEL; GATES, 2006). Dessa forma, a abordagem qualitativa difere da abordagem quantitativa a medida em que não emprega instrumentos estatísticos para análise 
de um problema de pesquisa, nem pretende numerar ou medir unidades de categorias homogêneas (RICHARDSON, 1989)

Dessa forma, pode-se dizer que o enfoque desta pesquisa é exploratório, já que essa tipologia visa prover o pesquisador de maior conhecimento sobre o problema de pesquisa (MATTAR, 2001). As pesquisas exploratórias tem o principal objetivo de proporcionar uma visão geral de determinado fato e são realizadas especialmente quando o tema escolhido ainda é pouco explorado e torna-se difícil estabelecer hipóteses precisas e operacionalizáveis (GIL, 2009).

De acordo com Gil (2009), habitualmente as pesquisas exploratórias, embora sejam bastante flexíveis, envolvem levantamento bibliográfico ou documental e estudos de caso. Nesta pesquisa serão utilizados estudos múltiplos de casos.

Para realização desta pesquisa, inicialmente foram coletados dados secundários com o objetivo de compor o referencial teórico acerca dos temas relacionados ao turismo, em especial na região de montanhas do Espírito Santo, ao setor de serviços e do marketing de relacionamento, a fim de obter uma base teórica para realização dos estudos de caso. Nesta primeira etapa foram realizadas pesquisas bibliográficas em livros, artigos científicos, periódicos e diretórios na internet, além de coleta de dados na Secretaria de Turismo de Marechal Floriano.

Quanto ao procedimento técnico utilizado nesta pesquisa, optou-se pelo estudo múltiplo de casos, pois considera-se que, a utilização de múltiplos casos, proporciona evidências de diferentes contextos, levando a elaboração de uma pesquisa de melhor qualidade (GIL, 2002). De acordo com Gil (2002, p. 54), o estudo de caso, "consiste no estudo profundo e axaustivo de um ou poucos objetos, de maneira que permita seu amplo e detalhado conhecimento". O estudo de caso permite uma investigação que preserva as características holísticas e relevantes dos acontecimentos da vida real, como ciclos de vida individuais, mudanças ocorridas em alguma região ou características de relacionamentos (YIN, 2005). No estudo de caso, os comportamentos únicos e as diferenças que destoam da maioria, são mostrados, não avendo a preocupação com a homogeineidade (GOLDENBERG, 2003). 


\subsection{Universo da amostra}

O universo da presente pesquisa é formado pelas pousadas do município de Marechal Floriano, cujos sujeitos da pesquisa, são seus dirigentes bem como seus clientes. As pousadas que serviram de amostra para a pesquisa são de porte pequeno e estão localizadas no distrito de Santa Maria, zona rural do município, onde as principais características são o clima frio e o intenso contato com a natureza. Para obtenção de dados, optou-se pela amostra nãoprobabilística intencional, constituída de três (03) pousadas do município de Marechal Floriano-ES. Na amostra não-probabilística intencional, os critérios de seleção da amostra são baseados no julgamento pessoal do pesquisador de que os elementos sejam representativos da população em estudo (MCDANIEL; GATES, 2006). Desta forma, optou-se por realizar a pesquisa com 03, das 08 pousadas existentes no município de Marechal Floriano, devido ao curto tempo destinado a pesquisa e por considerar-se, ser este um número suficiente e representativo para expor as estratégias de marketing de relacionamento utilizadas pelas pousadas, atualmente no município.

\subsection{Caracterização das pousadas}

Por se tratar de uma região ainda pouco conhecida no que diz respeito ao turismo, a demanda das pousadas do município de Marechal Floriano oscila entre alta e baixa no decorrer do ano. A maior parte dos clientes das pousadas são moradores da região metropolitana e procuram as pousadas principalmente no inverno, em feriados prolongados e quando há eventos na região. As pousadas que fazem parte desta pesquisa serão caracterizadas de acordo com elementos que são relevantes ao alcance dos objetivos deste estudo.

Pousada A

A pousada A, tem 05 anos de funcionamento e foi a primeira pousada a se instalar no distrito de Santa Maria, em Marechal Floriano. A pousada tem hoje 09 apartamentos em funcionamento e tem um projeto já em construção de mais 27 apartamentos. De acordo com a Dirigente A, esses novos apartamentos atenderão a dois níveis de hospedagem: 18 deles serão apartamentos simples, e 09 deles serão apartamentos considerados de nível médio por possuírem ar condicionado. Na pousada $\mathrm{A}$, trabalham atualmente 06 pessoas, sendo que destas, 04 são pessoas da família dos donos da pousada. Essas 04 pessoas são responsáveis 
pela recepção, acomodação, serviços relacionados ao bar e restaurante e a administração da pousada. Além destas, a pousada conta com 01 diarista que auxilia na cozinha, limpeza e arrumação dos quartos e 01 garçom que trabalha no bar.

A pousada oferece os serviços de hospedagem com cama e café ou pensão completa, conforme o cliente deseje, tem a disposição um salão de festas para locação, pesque-pague, área com jogos e com piscina. De acordo com a dirigente $\mathrm{A}$, além desses serviços, um outro atrativo e diferencial, é que a pousada conta com serviços de bar, restaurante e pizzaria para os clientes e para a comunidade. A dirigente da pousada A relata, que:

O desejo em ter uma pousada, surgiu ainda quando era criança, quando sonhava algo diferente daquela vida sofrida que vivia no interior (...) conheci a cidade grande e fiquei impressionada com tanta beleza, e imaginava um pouquinho de tanta beleza na minha terra. Bares, restaurantes, hotéis, lazer e muitas outras coisas interessantes (DIRIGENTE A).

\section{Pousada B}

A pousada B tem cerca de 01 ano de funcionamento e possui 04 chalés para hospedagem. Todo o trabalho na pousada desde a recepção, acomodação e serviços de alimentação, é realizado pela família. São cinco pessoas da família que trabalham na pousada, e segundo a dirigente $\mathrm{B}$, cada uma tem sua função e é importante de igual forma.

A pousada oferece os serviços de hospedagem com café da manha, ampla área de lazer com campo, área de churrasqueira e piscina. A pousada ainda oferece visitação a criação de animais silvestres, pacas e jacarés que são um atrativo a parte. Segundo a dirigente da pousada B, a visitação aos animais do sítio foi o que despertou o interesse em abrir uma pousada:

Nosso interesse em ter uma pousada, surgiu porque, (...) muitas pessoas vinham visitar o sítio, pra ver os animais, chegavam aqui e gostavam do lugar, aí falavam: "Por que vocês não fazem uma pousada?". Muitas pessoas falavam que queriam vir visitar o sítio, mas também queriam ter um lugar pra ficar, então a gente viu que poderia dar certo e resolvemos fazer as primeiras acomodações. Inicialmente fizemos dois chalés, e depois, devido à procura que teve, fizemos mais dois (DIRIGENTE B). 
Pousada C

A pousada $\mathrm{C}$ está em funcionamento há cerca de 01 ano e meio e possui hoje 04 suítes. A pousada possui um projeto de ampliação já em construção, e terá mais 8 suítes.

$\mathrm{Na}$ pousada $\mathrm{C}$, trabalham 03 sócios, sendo que o primeiro tem a função de recepcionar e atender os clientes, fazendo trilhas e passeios com os hóspedes, já o segundo gerencia as finanças da pousada e o terceiro é responsável por todas as atividades da pousada, limpeza, organização e alimentação. A pousada ainda conta com uma funcionária contratada para auxiliar na limpeza, cozinha e arrumação dos quartos. A pousada oferece serviços de hospedagem com cama e café ou pensão completa, aluga o espaço da pousada para eventos, oferece ainda pescaria, trilhas ecológicas, passeio de barco, e cachoeira para banho. A área da pousada é grande e muito bem arborizada, segundo a dirigente $\mathrm{C}$, "o espaço é maravilhoso para tirar fotografias". Segundo a dirigente da pousada C, a pousada surgiu a partir da preocupação de seu marido em querer dar uma vida tranquila a ela, e viu na pousada uma maneira de alcançar isso. Além disso, a família sempre recebeu muitos amigos em casa, o que despertou também o interesse nesse projeto:

\begin{abstract}
Nós morávamos em Vitória e vínhamos pra Marechal Floriano para passar os finais se semana. Todo final de semana que nós vínhamos pra cá, tinha sempre casais ou grupos de amigos nossos que vinham pra cá também, ficavam na nossa casa (...) só que no final das contas a gente foi percebendo que foi ficando pesado financeiramente (...). Um desses nossos amigos, certa vez falou que já que nossa casa era assim, vivia cheia de gente, nós podíamos fazer uma pousada e passar a cobrar pela hospedagem. (...) A partir da sugestão de um dos nossos amigos e de um dos candidatos a prefeito da época, nós começamos a pensar na possibilidade e acreditar que poderia dar certo (DIRIGENTE C).
\end{abstract}

\title{
3.3. Coleta de dados
}

De acordo com os objetivos da presente pesquisa, optou-se pela utilização de observação direta e entrevistas de profundidade. No que diz respeito a observação direta, Goldenberg (2003) menciona que a técnica, permite um acompanhamento mais minucioso de certa 
situação, complementando a técnica de entrevistas em profundidade. Esta, também chamada de entrevista não-estruturada, tem por objetivo, obter do entrevistado o que ele considera os aspectos mais relevantes de determinado problema e as suas descrições de uma situação em estudo. Por meio de uma conversa guiada, pretende-se obter informações que possam ser utilizadas em uma análise qualitativa. A entrevista não-estruturada procura conhecer como e porque algo ocorre, em lugar de determinar a frequência de certos fenômenos (RICHARDSON, 1989). As entrevistas semi-estruturadas do presente estudo, foram baseadas em um roteiro composto por oito questões para os dirigentes, do qual foi realizado pré-teste do roteiro de entrevista para verificar a clareza e compreensão das questões, bem como a ordem em que apareciam. As entrevistas ocorreram entre os dias 08 de outubro a 06 de novembro, sendo realizadas pelo autor da pesquisa e gravadas com o auxilio de um aparelho celular para posterior transcrição.

\subsection{Tratamento dos dados}

Após a coleta de dados, a partir das entrevistas de profundidade, iniciou-se a fase de análise dos dados. Os dados obtidos nas entrevistas foram tratados de forma predominantemente qualitativa, utilizando a análise das falas de cada um dos entrevistados. Dentre as técnicas qualitativas de análise e interpretação de dados, foi utilizada a técnica de emparelhamento que, segundo Laville e Dionne (1999, p. 227) consiste em "aparelhar ou, mais precisamente, em associar os dados recolhidos a um modelo teórico com a finalidade de compará-los". O uso da técnica de emparelhamento justifica-se uma vez que, a análise dos dados foi realizada sob a luz da teoria apresentada neste trabalho, fazendo-se uma comparação com os dados coletados em campo. 


\section{Análise e Discussão}

Os sujeitos da pesquisa foram identificados no texto como dirigentes A, B e C.

\subsection{Resultados e análise}

A discussão apresentada aqui perpassa no processo de construção de relacionamento duradouro entre as pousadas e seus clientes. Apresentar-se-á as principais ações desenvolvidas nesse processo.

Inicialmente, para a construção de um bom relacionamento e até mesmo uma boa impressão da pousada, os três dirigentes concordam que é preciso oferecer ao cliente um ambiente familiar. Porém, em uma época em que os clientes têm tanta informação, torna-se cada vez mais difícil criar uma imagem (MCKENNA, 1997), levar uma idéia a um cliente nem sempre é fácil e as percepções podem ser diferentes. As três pousadas pesquisadas possuem características semelhantes, e de acordo com seus dirigentes, buscam levar essa imagem de ambiente familiar. Essas características podem ser percebidas no fragmento 1:

As pessoas dizem que gostam muito de ficar aqui pelo sossego, tranquilidade e também pelo ambiente familiar. Nós costumamos receber mais famílias e casais, e as pessoas que trabalham aqui são todos da nossa família. Acho que isso contribui para criar esse ambiente familiar (DIRIGENTE B).

Quando os dirigentes citam que procuram proporcionar aos clientes um ambiente familiar, observam-se dois fatores importantes: o primeiro diz respeito às pessoas que trabalham na pousada. As três pousadas pesquisadas são empresas familiares, onde as pessoas da família são responsáveis pelas principais atividades.

Outro fator que segundo os dirigentes faz das pousadas um ambiente familiar, são os próprios hóspedes, na maioria dos casos, são casais com filhos ou sem filhos que procuram a pousada para descansar e gostam de tranquilidade, proporcionando um ambiente também tranquilo. Os hóspedes não são uma escolha dos donos da pousada, mas essas características comuns entre eles auxiliam na entrega, de acordo com os dirigentes, de um ambiente acolhedor e familiar.

Essas características comuns dos clientes podem ser verificadas por meio de observação, em casos mais simples, ou com o auxílio de uma das principais ferramentas do marketing de 
relacionamento, o banco de dados de clientes. O banco de dados contribui para a formação de relacionamentos duradouros, visto que, a empresa passa a conhecer melhor seu cliente e pode então, apresentar a eles a oferta ou serviços adequados (VAVRA, 1993).

Das pousadas pesquisadas, apenas duas possuem banco de dados, são elas a Pousada A e a Pousada C. A dirigente B disse que a pousada B ainda não possui banco de dados, mas já pensam em confeccionar fichas para controle dos hóspedes e sabe da importância de ter um banco de dados de clientes. As pousadas A e C que possuem banco de dados e utilizam mecanismos diferentes de acordo com os fragmentos 2 e 3 :

\begin{abstract}
A gente tem um banco de dados informatizado com informações dos clientes, como nome completo, telefone, endereço, e-mail. Normalmente essas informações são passadas por e-mail no momento da reserva, junto com o número de acompanhantes e o nome de cada um deles. Quando o cliente faz a reserva por telefone, quando ele chega à pousada a gente pede para ele se dirigir até ao balcão para fazer o check-in (DIRIGENTE A).

Para conhecer um pouco melhor o cliente, nós implantamos desde o começo do funcionamento da pousada, uma ficha de cadastro. No começo escreviase tudo à mão, (...), agora nós fizemos uma ficha em gráfica e a gente pede para as pessoas escreverem o nome completo, data de aniversário delas e dos acompanhantes, endereço, telefone e e-mail, são as informações principais (DIRIGENTE C).
\end{abstract}

No fragmento 2 pode-se perceber que, a pousada A utiliza planilhas de computador para fazer o banco de dados de seus clientes, todo o processo de reserva pode ser feito por e-mail e algumas vezes é a única forma de comunicação que existe entre a pousada e os clientes. A informática pode ser uma importante aliada para o marketing de relacionamento, pois proporciona memória organizacional e facilita os processos de organização e recuperação de dados (GORDON, 2002). Nas pousadas B e C, a comunicação e as reservas, são feitas em sua maioria por telefone.

Como descrito no fragmento 3 , a pousada $\mathrm{C}$ utiliza um cadastro dos hóspedes por fichas, que posteriormente são organizadas em planilhas de computador. No entanto, mesmo sendo um trabalho quase que manual, por meio de observação direta e pelos dados da entrevista de profundidade, pôde-se verificar total organização dessas fichas pela dirigente $C$, sendo que 
esta utiliza as informações coletadas para construção de um bom relacionamento com os clientes como demonstrado no fragmento 4 :

4. (...) colocamos (na ficha) a data de entrada e saída dos clientes da pousada e a gente consegue fazer um controle de frequiência através disso. Como a gente consegue ter a data de aniversário e o telefone, a gente sempre procura ligar aniversariando e depois que os hóspedes saem daqui, a gente liga pra saber se chegaram bem em casa, se a viajem foi boa, se gostaram do final de semana, essas coisas (DIRIGENTE C).

Um banco de dados eficiente, normalmente faz uso de tecnologias e de computador. A tecnologia é uma grande aliada no processo de formação do relacionamento, mas as pequenas empresas, como é o caso das pousadas pesquisadas, que às vezes não são nem informatizadas, precisam desenvolver outros mecanismos (BOWERSOX; COOPER; CLOSS, 2006). Mello e Vieira (2008) apresentam algumas dessas estratégias para pequenas empresas em seu trabalho, das quais se pode citar: atendimento cordial e contato com o cliente por telefone.

Essas estratégias apresentadas, no trabalho de Mello e Vieira (2008) são também as principais ações desenvolvidas nas pousadas de Marechal Floriano, que utilizam o bom atendimento e o contato direto com o cliente para satisfazê-lo e promover sua fidelização.

O fragmento 5 mostra a percepção de um dirigente com relação ao desenvolvimento de um bom atendimento:

Desde quando o cliente liga para fazer a reserva, a gente procura ter um atendimento cordial. (...) O principal motivo para que os hóspedes voltem à pousada, de acordo com eles mesmos, é por que gostam de mim e do meu marido. Eles sempre dizem que gostaram do atendimento, da nossa simpatia, que gostam muito da gente, assim, tem alguns clientes que não voltam, mais ligam para saber como a gente está, ou se está tudo bem na pousada (DIRIGENTE C).

Um fato comum entre as pousadas pesquisadas, é que os próprios donos são os responsáveis pela recepção e atendimento aos clientes. Esse fator pode, em muitos casos, elevar a qualidade do atendimento, e personalizar os serviços (GRÖNROOS, 2003). A dirigente A diz que seus clientes fazem questão de conversar com os "donos da casa" o que demonstra a acessibilidade 
e atenção que os donos da pousada dispensam aos clientes. Essa atenção, ou uma conversa informal na varanda da pousada, além de trazer certo vínculo de amizade, como já mencionado, pode também trazer para os donos, informações preciosas sobre os desejos, percepções e necessidades dos clientes. Dessa forma, os dirigentes serão capazes de conhecer melhor seus clientes e estarão proporcionando o contato face a face que são elementos estratégicos do marketing de relacionamento (GRÖNROOS, 2003).

Além do retorno dos hóspedes, e até mesmo maior conhecimento dos clientes, um bom atendimento desencadeia um processo muito importante para pequenas empresas e que utilizam estratégias de marketing de relacionamento, a propaganda boca a boca (MOTA; FREITAS, 2008). A recomendação de alguém que já se hospedou na pousada e desfrutou de todos os serviços ofertados torna-se mais relevante do que qualquer propaganda em mídia, pois traz mais credibilidade à empresa. No fragmento 9 , pode-se verificar essa ferramenta, quando a dirigente A diz que os hóspedes que gostam da pousada, retornam com outras pessoas.

Para desenvolver um bom atendimento e satisfazer os clientes, as pousadas pesquisadas costumam dar liberdade para os clientes escolherem, por exemplo, o que querem comer, ou o que querem fazer. Essa característica pode ser observada no fragmento 6.

Aqui a gente procura deixar eles (os clientes) muito a vontade para escolher o que eles querem comer, eu mostro opções de cardápio para eles escolherem. Eles escolhem o que querem fazer, e a gente faz junto, fica bem a critério dos hóspedes como eles querem passar o final de semana, a gente indica lugares por perto pra eles conhecerem, às vezes vamos junto com eles para mostrar. Eu tenho até para as próximas semanas um grupo que vai vir e gosta de forró e quer um lugar pra fazer um forrozinho, a gente vai tirar as mesas do lugar e vai dar um jeito pra eles fazerem. (...) A gente procura muito ouvir o que o cliente quer fazer pra melhor poder atendê-los e já por telefone diz quais são nossas opções de cardápio e de lazer, e o cliente já diz o que ele quer almoçar por exemplo. (...) A gente começou oferecendo cama e café, mas fomos percebendo que as pessoas queriam vir, se hospedar, e não precisar sair da pousada pra almoçar, então a gente oferece refeições também, tudo pra que o cliente se sinta melhor possível (DIRIGENTE C).

Nesse sentido, Grönroos (2003) destaca que, um dos elementos táticos de uma estratégia de relacionamento, é desenvolver um sistema de serviços que seja orientado para o cliente, ou 
seja, os processos de geração de valor da empresa devem ser voltados para os interesses e necessidades dos clientes com o intuito de satisfazê-los. Dessa forma, as pousadas parecem estar seguindo esta tática e entregando ao cliente os serviços que a eles interessa.

Outra estratégia utilizada pelas pousadas para fidelizar os clientes, é o contato por telefone com eles, quando não estão hospedados. Em empresas, a comunicação externa tem o papel de facilitar a interação entre a empresa e seus clientes, e com os avanços tecnológicos, a principal forma de comunicação utilizada é a internet (GORDON, 2002). No entanto, nas pousadas pesquisadas a principal forma de comunicação é o telefone, sendo que uma pequena maioria mantém também, contato pela internet. A pousada A tem o próprio site já em funcionamento, a pousada B está construindo seu site e a pousada C não possui site, mas participa de sites de relacionamento. Além disso, no site da Prefeitura de Marechal Floriano tem a relação de todas as pousadas com endereço, telefone e e-mail. Este contato externo com os clientes pode ser desenvolvido para informar, por exemplo, sobre promoções ou novidades (MELLO; VIEIRA, 2008). Os fragmentos 7 e 8 demonstram como as pousadas utilizam essa técnica:

\begin{abstract}
A gente procura comunicar a alguns clientes nossos, por telefone, quando tem algum evento aqui no município, a gente comunica àqueles mais próximos e que vem com maior frequência, mas eu estou pensando em mandar alguns comunicados também por e-mail. Nós temos cadastrados hoje pouco mais de 1 mil e-mails (...). Eu estou esperando acabar a reforma aqui pra pensar melhor sobre como desenvolver isso (DIRIGENTE A).

Tem alguns clientes que acabam se tornando amigos mesmo, então quando tem alguma festa aqui por perto e a gente sabe que eles gostam de vir, a gente liga pra avisar, pra convidar (DIRIGENTE B).
\end{abstract}

Nos fragmentos acima, pode-se observar que nas pousadas, o contato por telefone é realizado para comunicar eventos na pousada ou em lugares vizinhos. Outro ponto a se observar, é que o contato não é feito com todos os clientes, e sim com os mais frequentes ou que acabam se tornando amigos. O marketing de relacionamento, para ser eficiente, deve ser desenvolvido com grupo de clientes estratégicos, com aqueles que representam maior valor para a empresa (BOWERSOX; COOPER; CLOSS, 2006). Desenvolver ações com todos os clientes demanda um investimento alto que pode não ter o retorno desejado. 
Muitas empresas estão percebendo que é mais vantajoso cooperar para competir (TONI; SCHULER, 2004). Formar parcerias com outras pousadas ou com fornecedores pode ser um importante meio de dividir despesas e alcançar credibilidade (MCKENNA, 1997), nesse sentido, as pousadas pesquisadas utilizam algumas formas de parceria como demonstrado nos fragmentos abaixo:

Hoje, nós fazemos parceria com a empresa que administra o trem das montanhas, que vem até Araguaia. A gente oferece transporte e uma cortesia a noite, que é uma pizza média, para as pessoas que vem com o trem e desejam passar a noite aqui, ou ainda dois caldos, como o cliente preferir. (...) Quando nossa pousada já está com a capacidade máxima ocupada, a gente procura indicar as pousadas mais perto para que o cliente se hospede. Durante o dia, a gente também indica outros lugares para os clientes conhecerem. Agora nós fizemos uma parceria também com um restaurante que serve porção de traíra, o cliente que está hospedado aqui se for lá almoçar tem $20 \%$ de desconto, ele leva um vale e tem direito ao desconto. Desta forma com que a gente trabalha, fazendo essas parcerias, eu vejo que meus clientes têm mais opções de lazer, minha intenção não é prender meu cliente aqui na pousada, muito pelo contrário, minha intenção é que ele aproveite o máximo o dia conhecendo outros empreendimentos para que ele volte. (DIRIGENTE A).

As pousadas pesquisadas têm em comum o fato de indicarem outras pousadas para os clientes, se ocorrer de a sua estar com lotação máxima. De acordo com a Dirigente $\mathrm{C}$, essas indicações ainda são pequenas, mas já ocorre e faz com que o cliente se sinta agradecido e queira conhecer a pousada em uma próxima oportunidade. Neste caso, a pousada pode não buscar uma venda imediata, mas a indicação de outra pousada para um cliente demonstra capacidade para atender às suas necessidades de forma superior (KOTLER; KELLER, 2006), e os dirigentes demonstram ter conhecimento com relação a este fator, quando relatam que o cliente desejará conhecer as pousadas em uma próxima vez.

Como demonstrado, o estabelecimento de parcerias pode ser uma forma de satisfazer os hóspedes, criando mais opções de lazer ou entregando maior valor nos serviços. A satisfação pode ser criada também por meio da personalização do atendimento e dos serviços e pode ser medida por meio do índice de retorno (GILBERTI; JEUNON; ANDRADE, 2007). Medir a satisfação dos clientes deve ser considerado uma estratégia para melhorar o relacionamento. No entanto, as pousadas pesquisadas não utilizam nenhum tipo de pesquisa, todo o processo 
de investigação da satisfação de seus clientes é verbal, e todas demonstram ter a preocupação de saber se estão satisfazendo os clientes.

Normalmente o maior sinal de que um relacionamento não vai bem, é a falta de reclamação, dificilmente alguém estará satisfeito todo o tempo e neste caso é importante sim, procurar o cliente para saber sua opinião (LEVITT, 1990). Nesse sentido, Santos e Fernandes (2007) concluíram, em pesquisa realizada sobre a recuperação de serviços e seu efeito na confiança e lealdade do cliente, que a maneira como as reclamações são resolvidas tem papel de total importância na manutenção e desenvolvimento de relacionamentos de longo-prazo.

Solicitar a opinião de um cliente é importante para a formação de relacionamentos de longo prazo, pois faz o cliente se sentir reconhecido e relevante para a empresa (VAVRA, 1993). Pode-se também destacar, que a Pousada C parece ter conseguido alcançar, um nível de relacionamento muito bom com seus clientes. A Dirigente $\mathrm{C}$ menciona que utilizava uma "caixa de sugestões", mas deixou de usar, pois os clientes preferiam dar suas sugestões pessoalmente a ela. Esse fato demonstra que a dirigente $\mathrm{C}$ conseguiu conquistar a confiança de seus clientes e fazer com que eles se sentissem a vontade e confortáveis para expressarem suas opiniões, fato bastante relevante, pois o marketing de relacionamento sugere a interação e confiança entre empresa e cliente (MELLO; VIEIRA, 2008).

\section{Considerações Finais}

A presente pesquisa teve por objetivo, identificar e descrever quais estratégias de marketing de relacionamento as pousadas de Marechal Floriano/ES estão desenvolvendo junto a seus clientes. Através de entrevistas de profundidade com os dirigentes de três pousadas do município foi alcançado este fim.

Com as entrevistas realizadas e por observação, verificou-se que as pousadas utilizam ações de marketing de relacionamento, mas sem saber que as praticam. Os dirigentes entrevistados pouco sabiam sobre o assunto, mas se mostraram receptivos e interessados nos resultados da pesquisa. 
As principais ações de marketing de relacionamento observadas nas pousadas foram: a boa receptividade e o atendimento cordial. Vale salientar que mesmo destacando-se o atendimento cordial, as pousadas utilizam elementos e técnicas semelhantes, e outros particulares, para satisfazer seus clientes. As técnicas mais observadas foram: entrega de sossego e um ambiente tranqüilo, dito familiar; deixar o cliente à vontade para escolher o que comer ou fazer; simpatia dos atendentes; contato próximo entre os donos das pousadas e os clientes, e formação de vínculos de amizade.

Além de um bom atendimento, foi verificado que as pousadas procuram manter contato, por telefone ou e-mail, com os clientes para comunicar sobre eventos e programações. Este contato é feito apenas com grupos de clientes mais próximos e mais frequentes, sendo este um dos princípios do marketing de relacionamento, determinar grupos de clientes com maior valor para receber as ações.

As pousadas também realizam parcerias com outros empreendimentos, indicando restaurantes para seus hóspedes e até mesmo indicando outras pousadas para possíveis clientes se a sua já estiver com capacidade máxima. Esse tipo de parceria agrada aos clientes que passam a ter mais opções de lazer e confiança nos dirigentes, que por sua vez, passam a ter mais credibilidade com os clientes.

Outro elemento do marketing de relacionamento encontrado em pelo menos duas das pousadas é o banco de dados de clientes, uma ferramenta fundamental para formação de relacionamentos de longo prazo. Mesmo a pousada que ainda não possui banco de dados, sabe da importância de tê-lo e já está trabalhando para implantá-lo. Logo, podemos dizer que esta é uma ação presente nas pousadas que ajudará na manutenção de relacionamentos duradouros.

Diante do que foi apresentado neste trabalho, sugere-se para pesquisas futuras um estudo mais detalhado a respeito das ações de marketing nas pousadas do município de Marechal Floriano. Além disso, podem ser realizadas pesquisas comparativas, entre as ações de marketing de relacionamento desenvolvidas nas pousadas de Marechal Floriano e em pousadas de municípios vizinhos. 


\section{Referências}

BARNES, J. G. Segredos da gestão pelo relacionamento com os clientes - CRM: é tudo uma questão de como você faz com que eles se sintam. Rio de Janeiro: Qualitymark, 2002.

BARRETO, M. Manual de Iniciação ao Estudo do Turismo. 17. Ed. Campinas: Papirus, 2003.

BOWERSOX, D. J; COOPER, M. B; CLOSS, D. J. Gestão Logistica de cadeia de Suprimentos. New York: Bookman, 2006.

BREI, V. A.; ROSSI, C. A. Confi ança, valor percebido e lealdade em trocas relacionais de serviço: um estudo com usuários de internet banking no Brasil. RAC. Revista de Administração Contemporânea, v. 9, n. 2, p. 145-168, 2005.

FUTURA. Montanhas capixabas. Disponível em:< http://www.futuranet.ws/upld/pesquisa/semanal/183/arquivo/R_Site_MontanhasCapixabas.pd f>. Acesso em 12 ago 2011.

GIL, A. C. Como elaborar projetos de pesquisa. 4. ed. São Paulo: Atlas, 2002. . Métodos e técnicas de pesquisa social. 6. ed. 2. reimpre. São Paulo: Atlas, 2009.

GILBERTI, F.; JEUNON, E. E.; ANDRADE, M. L. Influência do marketing de relacionamento na repetição de compra dos clientes de telefonia móvel de Belo Horizonte. Gestão \& Tecnologia, v. 8, jan-jul. 2007.

GOLDENBERG, M. A arte de pesquisar: como fazer pesquisa qualitativa em ciências sociais. 7. ed. Rio de Janeiro: Record, 2003.

GORDON, I. Marketing de relacionamento: estratégias, técnicas e tecnologias para conquistar clientes e mantê-los para sempre. 5. ed. São Paulo: Futura, 2002.

Marketing de relacionamento. Estratégias, técnicas e tecnologias para conquistar clientes e mantê-los para sempre. São Paulo: Futura, 1998.

GOUVÊA, A. M.; YAMAUCHI, E. C. I. Marketing de Serviços: Uma visão do Turismo no Brasil. Caderno de Pesquisas em Administração, São Paulo, v. 1, n. 9. 1999.

GOUVÊA, M. A,; NIÑO, F. M. Marketing de turismo e o advento da internet: os desafios das empresas de serviços turísticos no terceiro milênio. REAd. Revista Eletrônica de Administração, v. 12, n. 2, mar-abr. 2006.

GOUVEA, M. A.; BIAZZI, M. R. O comportamento do consumidor do setor

farmacêutico diante da demanda não atendida - implicações para a cadeia de suprimentos. RAM. Revista de Administração Mackenzie, v. 08, n. 1, p. 12-30, 2007.

GRÖNROOS, C. Marketing: gerenciamento e serviços. 2. ed. Rio de Janeiro: Elsevier, 2003.

KOTLER, F.; ARMSTRONG, G. Princípios de marketing. 9. ed. São Paulo: Pearson Prentice Hall, 2003.

KOTLER, P.; KELLER, K. L.; Administração de marketing. 12. ed. São Paulo: Pearson Prentice Hall, 2006.

LACERDA, R. A. Gestão hoteleira em pousadas da 702 Sul. Monografia (Especialização em Formação de Consultores de Turismo) - Curso de Especialização em Formação de Consultores de Turismo, Universidade de Brasília, 2008. Disponível em: < 
http://bdm.bce.unb.br/bitstream/10483/421/1/2008_ReginaAlmeidaLacerda.pdf $>$. Acesso em: 20 jul. 2011.

LAKATOS, E. M.; MARCONI, M DE. A. Fundamentos de metodologia científica. 4. ed. Revista e Ampliada. São Paulo: Atlas 2001.

LAVILLE, C; DIONNE, J. A construção do saber: manual de metodologia da pesquisa em ciências humanas. Porto Alegre: Editora Artmed.; Belo Horizonte: Editora UFMG, 1999.

LEVITT, T. A imaginação de marketing. 2. ed. São Paulo: Atlas, 1990.

MATTAR, F. N. Pesquisa de Marketing. Edição compacta. 3. ed. São Paulo: Atlas, 2001.

MCDANIEL, C.; GATES, R. Pesquisa de Marketing. São Paulo: Thomson Learning, 2006.

MCKENNA, R. Marketing de Relacionamento: estratégias bem-sucedidas para a era do cliente. 20. ed. Rio de Janeiro: Elsevier, 1997.

MELLO, C. M de; VIEIRA, F. G. D. Marketing de relacionamento: um estudo empírico em micro e pequenas empresas do comercio varejista de Campo Mourão/PR. Perspectivas Contemporâneas, Campo Mourão, v. 03, n. 01, p. 109-130, jan-jul. 2008.

MOTA, M. de O.; FREITAS, A. A. F. Análise dos Benefícios Relacionais Observados por Usuários de Serviços. RAM. Revista de Administração Mackenzie, V. 9, set/out 2008, 126-147.

NEGRETTO, R. J. Fidelização de clientes bancários: marketing de relacionamento como base na estratégia de lealdade. 2007. 54 f. Trabalho de conclusão de curso (especialização) - Programa de Pósgraduação em Gestão em administração, Universidade Federal do Rio Grande do Sul, Porto Alegre, 2007.

NICKELS, W. G.; WOOD, M. B. Marketing: relacionamentos, qualidade, valor. Rio de Janeiro: LTC, 1999.

OLBRZYMEK, J. R.; OLBRZYMEK, M. R.; BRETZKE, R. O. Marketing de relacionamento: grandes projetos não envolvem somente tecnologia. Revista Agathos, ano I, n. 1, 2005.

PEPPERS, D.; ROGERS, M. Marketing um a um: marketing individualizado na era do cliente. Rio de Janeiro: Campus, 1994.

RIBEIRO, A.; FLEURY, A. Marketing e serviços que ainda fazem a diferença. São Paulo: Saraiva, 2006.

RICHARDSON, R. J. Pesquisa social: métodos e técnicas. 2. ed. São Paulo: Atlas, 1989.

ROCHA, A DA.; LUCE, F. B. Relacionamento entre Compradores e Vendedores: origens e perspectivas no Marketing de Relacionamento. RAE. Revista de Administração de Empresas, vol. 46, n. 3, jul-set. 2006.

SALIBY, P. E. O marketing de relacionamento: o novo marketing da nova era competitiva. RAE. Revista de Administração de Empresas, vol. 37, n. 3, jul-set. 1997.

SECRETARIA DE ESTADO DO TURISMO DO ESPIRITO SANTO. Plano de desenvolvimento sustentável da região turística: região montanhas capixabas. 2006. Disponível em: < http://www.turismo.es.gov.br/_midias/pdf/444-4c98baa01e74f.pdf>. Acesso em: 15 jun. 2011.

SECRETARIA DE TURISMO DO ESPÍRITO SANTO. Anuário do turismo no Espírito Santo. 2010. Disponível em: $<$ http://www.turismo.es.gov.br/_midias/pdf/664-4cd1849adf363.pdf>. Acesso em: 15 jun. 2011. 
SILVA, S. F. Marketing de Serviço: fundamentos, análises e prática no Setor de Saúde. Maceió: EDUFAL, 2008.

TONI, D.; SCHULER, M. A construção do relacionamento entre a vinícola miolo e seus fornecedores de uva: um estudo comparativo. REAd. Revista Eletrônica de Administração, v. 10, n. 04, jul-ago. 2004.

VAVRA, T. G. Marketing de relacionamento: aftermarketing. São Paulo: Atlas, 1993.

YIN, R. K. Estudo de caso: Planejamento e método. 3. ed. Porto Alegre: Bookman, 2005.

Recebido em: 15/04/2012 (1 ${ }^{\text {a }}$ versão) $10 / 12 / 2012$ ( $2^{\text {a }}$ versão)

Aprovado em: 11/12/2012 